\title{
Insulin and glucose mediate opposite intracellular ionized magnesium variations in human lymphocytes
}

\author{
P Delva, M Degan, M Trettene and A Lechi \\ Department of Biomedical and Surgical Sciences, Section of Medicina Interna C, University of Verona, Policlinico GB Rossi, Piazzale LA Scuro, 37134 Verona, \\ Italy \\ (Requests for offprints should be addressed to P Delva; Email: pietro.delva@univr.it)
}

\begin{abstract}
Insulin is capable of increasing intracellular magnesium, although very little is known about the effect of insulin on the biologically active fraction of magnesium, i.e. the ionized quota $\left(\mathrm{Mg}_{i}^{2+}\right)$, its interactions with glucose, and the cellular mechanisms involved in these processes. We studied the interactions of the effects of insulin and glucose on intracellular ionized magnesium in human lymphocytes. $\mathrm{Mg}_{i}^{2+}$ was measured using a fluorimetric method and the $\mathrm{Mg}^{2+}$-sensitive dye, furaptra. We found that insulin significantly increases the $\mathrm{Mg}_{i}^{2+}$ (without insulin $227 \pm 14 \mu \mathrm{M}$, with $10 \mu \mathrm{U} / \mathrm{ml}$, insulin $301 \pm 30 \mu \mathrm{M}, \quad P<0 \cdot 0001, n=12)$ in a dose-dependent manner in all three glucose concentrations tested $(5,7$ and $15 \mathrm{mmol} / \mathrm{l})$. The half-maximal effect of insulin was
\end{abstract}

approximately $0.8 \mu \mathrm{U} / \mathrm{ml}$. Glucose and insulin showed opposite effects in their ability to modify $\mathrm{Mg}_{i}^{2+}$ in lymphocytes. Inhibitors of the membrane $\mathrm{Na}^{+}-\mathrm{Mg}^{2+}$ transport system and of phosphatidylinositol (PI) 3-kinase abolish the insulin-mediated increase of $\mathrm{Mg}_{i}^{2+}$, thus suggesting that insulin is capable of increasing $\mathrm{Mg}_{i}^{2+}$ by modulating the activity of this transport system, possibly through the mediation of PI 3-kinase activation. Taking into account the relationship between insulin and glucose plasma levels and their opposing effects on $\mathrm{Mg}_{i}^{2+}$, this mechanism may represent the two limbs of a biphasic regulatory system of $\mathrm{Mg}_{i}^{2+}$ in both physiological and pathological conditions.

Journal of Endocrinology (2006) 190, 711-718

\section{Introduction}

A potential role of magnesium deficiency in the pathogenesis of type 2 diabetes mellitus has been recently proposed based on epidemiological, nutritional, and experimental data. In fact, large observational studies have described an association between low serum magnesium levels and type 2 diabetes (Ma et al. 1995). Accordingly, magnesium supplementation might be useful in the prevention and treatment of diabetes (Schnack et al. 1992). In vitro studies have shown an effect of magnesium on insulin secretion by the pancreas and on the mechanism of peripheral insulin resistance (Hwang et al. 1993). Our group has shown that intracellular ionized magnesium $\left(\mathrm{Mg}_{i}^{2+}\right)$ concentrations are decreased in patients with insulin resistance syndrome (Delva et al. 1996, 1998a) and that peripheral insulin resistance is related to $\mathrm{Mg}_{i}^{2+}$ levels (Delva et al. 1998b). Furthermore, we have shown in vitro that high extracellular glucose at concentrations compatible with those found in diabetes can reduce the concentration of $\mathrm{Mg}_{i}^{2+}$ (Delva et al. 2002). Insulin has been shown to increase the $\mathrm{Mg}_{i}^{2+}$ concentration in human erythrocytes (Barbagallo et al. 1993, 1997), platelets (Hwang et al. 1993), and the total intracellular magnesium in rat ventricular myocytes (Romani et al. 2000), and prevents $\mathrm{Mg}^{2+}$ extrusion induced by isoproterenol (Romani et al. 2000). Nonetheless, very little is known about the effect of insulin on the biologically active fraction of magnesium, i.e. the ionized quota, in nucleated human-derived cells, its interactions with glucose, and the cellular mechanisms involved. We have studied the interactions between insulin and glucose on $\mathrm{Mg}_{i}^{2+}$ in human lymphocytes in order to shed light on the cellular mechanisms involved in these processes.

\section{Material and Methods}

\section{Reagents}

The Ficoll-Histopaque reagent was obtained from Sigma Chemical, as were the RPMI 1640, BSA free fatty acids, and all the sugars utilized. $\mathrm{MgCl}_{2}$, lanthanum oxide (ultrapure grade), wortmannin, vandate and insulin were obtained from Sigma. Furaptra-acetoxymethyl ester and fura-2 acetoxymethyl ester were provided by Molecular Probes Inc. (Eugene, OR, USA).

\section{Preparations of human lymphocytes}

All studies were performed on human lymphocytes obtained from the local blood bank from healthy blood donors. Consent was obtained from the subjects after the nature of the 
procedure was explained. Peripheral blood lymphocytes were isolated as follows: total blood was diluted with RPMI 1640 medium (HEPES modification, glucose-free and supplemented with $\mathrm{MgSO}_{4}$ to reach the concentration of $0.8 \mathrm{mM}$ ) and layered carefully onto Histopaque 1077 and then centrifuged for $30 \mathrm{~min}$ at $400 \mathrm{~g}$. The layer of lymphocytes was carefully aspirated and washed twice in RPMI 1640 for $10 \mathrm{~min}$ at $150 \mathrm{~g}$. The cells thus obtained were allowed to sediment for $30 \mathrm{~min}$ in culture flasks. The supernatant was then transferred into tubes and centrifuged, and the lymphocytes thus obtained were resuspended in the same medium. The percentage of lymphocytes always exceeded 95\% and the vitality assessed as Trypan Blue exclusion was always higher than $97 \%$.

\section{Measurement of free intralymphocyte magnesium}

We used the method previously described by Delva et al. (1996). Lymphocytes were counted by means of a Coulter Counter (Coulter Electronics Ltd, Dunstable, Beds, UK). The cells were washed three times with RPMI 1640 and then three separate aliquots of lymphocytes $\left(6 \times 10^{6}\right.$ cells each) were suspended in RPMI 1640 with insulin (or the relevant substance) and three aliquots $\left(6 \times 10^{6}\right.$ cells each) without insulin (control cells). In some experiments, when the concentration of extracellular $\mathrm{Mg}^{2+}$ was varied, RPMI 1640 was substituted with Bulher solution containing (in $\mathrm{mM}$ ) $\mathrm{NaCl} 145, \mathrm{KCl} 5, \mathrm{Na}_{2} \mathrm{HPO}_{4} 0 \cdot 5$, HEPES 10 , $\mathrm{CaCl}_{2} 1, \mathrm{MgSO}_{4} 0-3$. All the aliquots had BSA $0 \cdot 1 \%(\mathrm{v} / \mathrm{v})$ and the cell permeant furaptra-acetoxymethyl ester $10 \mu \mathrm{M}$ added to them for $1 \mathrm{~h}$ at $37^{\circ} \mathrm{C}$. After centrifugation, the cells were washed twice in the same medium to remove extracellular dye and resuspended in the same medium at room temperature for $45 \mathrm{~min}$ for complete deesterification of the dye. For the measurement of intracellular $\mathrm{Mg}^{2+}$, the buffer utilized contained (in $\mathrm{mM}$ ) $140 \mathrm{NaCl}, 5 \mathrm{KCl}, 1 \cdot 8$ $\mathrm{CaCl}_{2}, 0 \cdot 8 \mathrm{MgSO}_{4}$, and $15 \mathrm{HEPES}$ with or without insulin for the insulin-incubated aliquots and without insulin for the insulin-free aliquots $\left(\mathrm{pH} 7 \cdot 4\right.$ at $\left.31^{\circ} \mathrm{C}\right)$. After washing off the 1640 medium, the cells were added to the above prewarmed medium $\left(31{ }^{\circ} \mathrm{C}\right)$ just before the fluorimetric measurements were performed. Fluorescence emission at $510 \mathrm{~nm}$ (slit width $10 \mathrm{~nm}$ ) was measured with alternate excitation at 335 and $370 \mathrm{~nm}$ (slit width $10 \mathrm{~nm}$ ) within a thermostatically controlled cuvette holder $\left(31^{\circ} \mathrm{C}\right)$ in a Hitachi F-2000 fluorescence spectrophotometer. Autofluorescence contributed to less than $1 \%$ of the total fluorescence values. One centimeter quartz cuvettes were used for all experiments. After reading the initial fluorescence emission resulting from excitation at 335 and $370 \mathrm{~nm}, 5 \mathrm{mM}$ EDTA and $5 \mathrm{mM}$ EGTA were added to the cuvette. Since extracellular $\mathrm{Mg}^{2+}$ and $\mathrm{Ca}^{2+}$ were chelated in the medium, a rapid-step change in fluorescence at both wavelengths occurred due to dye leaking from inside the cells. The immediate $(<10 s)$ change in fluorescence intensities at both wavelengths after the addition of EDTA and EGTA was considered in order to calculate the free resting intracellular $\mathrm{Mg}^{2+}$. Triton $\mathrm{X}-100$ was then added to a final concentration of $0 \cdot 1 \%(\mathrm{v} / \mathrm{v})$ to lyse the cells, and since the cells were in a medium containing EDTA and EGTA, it was possible to determine the minimum fluorescence ratio, $R_{\text {min }}$. Subsequently, $\mathrm{MgSO}_{4}(100 \mathrm{mM})$ was added to obtain the maximum fluorescence ratio, $R_{\max }$. Intracellular-free $\mathrm{Mg}$ was measured in triplicate and was calculated according to (Raju et al. 1989). The $K_{\mathrm{d}}$ of intracellularly generated furaptra for $\mathrm{Mg}^{2+}$ in our experimental condition was calculated to be $2 \cdot 1 \mathrm{mM}$ as previously described (Delva et al. 2004).

\section{Measurement of free intralymphocyte magnesium in the cytosol and intracellular organelles}

We performed an indirect estimate of $\mathrm{Mg}_{i}^{2+}$ in the cytosol and intracellular organelles of lymphocytes, both in the presence of insulin and in its absence, by differential permeabilization of the cells (Delva et al. 2004). We used the procedure described above to measure lymphocyte steady-state $\mathrm{Mg}_{i}^{2+}$ further by adding, after the addition of EGTA/EDTA mixture, digitonin $(25 \mathrm{mg} / \mathrm{l})$ in order to permeabilize the cell plasma membrane. In this condition, the cytosolic free magnesium is expected to leave the cell following its outwardly directed gradient and all the fluorescence measured is derived from intracellular organelles. Then, we indirectly calculated the cytosolic free magnesium concentration by subtracting the magnesiumfree concentration in the organelles from the lymphocyte steady-state $\mathrm{Mg}_{i}^{2+}$ concentration of the cell.

\section{Measurement of free intralymphocyte calcium}

The intracellular $\mathrm{Ca}^{2+}$ of lymphocytes was measured using fura-2 as previously described by Delva et al. (1996). Six aliquots of cells $\left(6 \times 10^{6}\right.$ each) were incubated following the same strategy used for $\mathrm{Mg}_{i}^{2+}$ determinations (with or without insulin) with $5 \mu \mathrm{M}$ fura-2-acetoxymethyl ester for $1 \mathrm{~h}$ at $37^{\circ} \mathrm{C}$, and then washed twice and left for $45 \mathrm{~min}$ at room temperature before any measurements were made. For fluorimetric measurements, the same buffer used for $\mathrm{Mg}_{i}^{2+}$ assay was utilized and the cells were added to a pre-warmed medium with a technique similar to that used for the $\mathrm{Mg}_{i}^{2+}$ assay. EGTA $(10 \mathrm{mM})$ was added to chelate $\mathrm{Ca}^{2+}$ in the medium, thus producing a desaturation of fura-2, which leaked from inside the cells, and giving a rapid-step change in fluorescence emission at $510 \mathrm{~nm}$ with excitation set at both 340 and $380 \mathrm{~nm}$ wavelengths. This provided the ratio values for the intracellular $\mathrm{Ca}^{2+}$ resting calculation (Grynkiewicz et al. 1985) using a $K_{\mathrm{d}}$ value for $175 \mathrm{nM} \mathrm{Ca}^{2+} /$ fura-2 complex as previously calculated in our experimental conditions (Delva et al. 2004). 
The intra- and inter-assay variability (coefficient of variation) determinations were $5 \cdot 8$ and $3.9 \%$ for ionized $\mathrm{Mg}_{i}^{2+}$ and $4 \cdot 6$ and $12 \cdot 7 \%$ for ionized $\mathrm{Ca}_{i}^{2+}$ determinations.

\section{Measurement of total intralymphocyte magnesium}

We utilized the method described by Elin and Hosseine (1985) with some modifications as previously described (Delva et al. 2004).

\section{Measurement of intralymphocyte ATP}

ATP content of human lymphocytes was measured as described by Nieminen et al. (1990) with minor variations (Delva et al. 2004).

\section{Statistical analysis}

Results are expressed as means \pm s.D. if no other method is specified. Comparison between groups was performed using Student's $t$-test and considered statistically significant when the probability of the null hypothesis was below at least $5 \%$. Confidence limits for differences in means were also provided. For multiple comparisons, a one-way ANOVA test with Bonferroni's correction for multiple comparisons was used.

\section{Results}

Effect of insulin on the intralymphocyte ionized magnesium concentration

The steady-state $\mathrm{Mg}_{i}^{2+}$ in the incubation media without insulin was $227 \pm 14 \mu \mathrm{M}(n=12)$. Incubation of lymphocytes for $2.5 \mathrm{~h}$ with $10 \mu \mathrm{U} / \mathrm{ml}$ insulin significantly increased this value $(301 \pm 30 \mu \mathrm{M}, P<0 \cdot 0001,95 \%$ confidence interval: 49-96 $\mu \mathrm{M}, n=12$ ) (Fig. 1C). Dose-response curves of $\mathrm{Mg}_{i}^{2+}$ to insulin at three extracellular glucose concentrations $(5,7$, and $15 \mathrm{mmol} / \mathrm{l}$ ) are shown in Fig. 1A. The effect of insulin on $\mathrm{Mg}_{i}^{2+}$ appears to be dose-dependent in all three extracellular glucose concentrations tested, with a half-maximal effect $\left(\mathrm{EC}_{50}\right)$ of approximately $0 \cdot 8 \mu \mathrm{U} / \mathrm{ml}$ insulin. Three statistically different maximal $\mathrm{Mg}_{i}^{2+}$ values were found (glucose: $5 \mathrm{mmol} / \mathrm{l}, 277 \pm 38 ; 7 \mathrm{mmol} / 1,231 \pm 40 ; 15 \mathrm{mmol} / \mathrm{l}, 204 \pm$ 35; ANOVA: $F=3 \cdot 5, P<0 \cdot 01, n=6)$. In Fig. $1 \mathrm{~B}$, the time course of the increase of $\mathrm{Mg}_{i}^{2+}$ by $10 \mu \mathrm{U} / \mathrm{ml}$ insulin is measurable after $30 \mathrm{~min}$, reaching a maximal effect after $120 \mathrm{~min}$. The in vitro effects of insulin comparisons to IGF-1 and insulin-mimetic stimuli, glucose analogs, inhibitors of insulin signaling and inhibitors of glucose metabolism are summarized in Table 1. The interrelationships between the in vitro effects of insulin and inhibitors or regulators of transmembrane $\mathrm{Mg}^{2+}$ fluxes in human lymphocytes are summarized in Table 2.

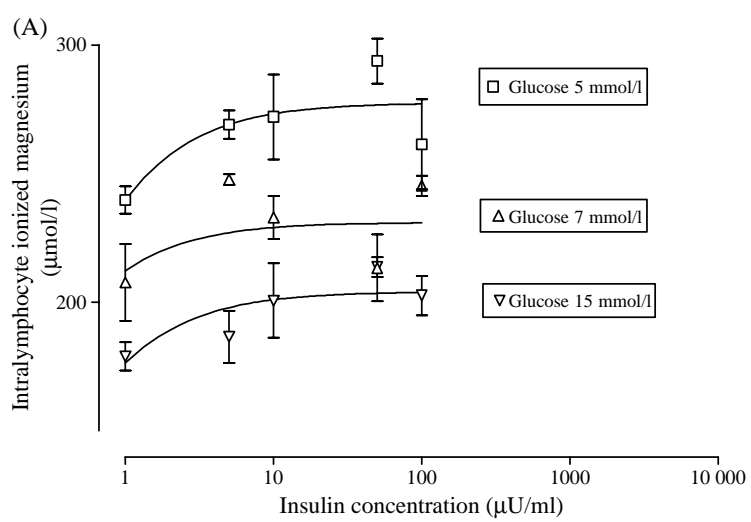

(B)
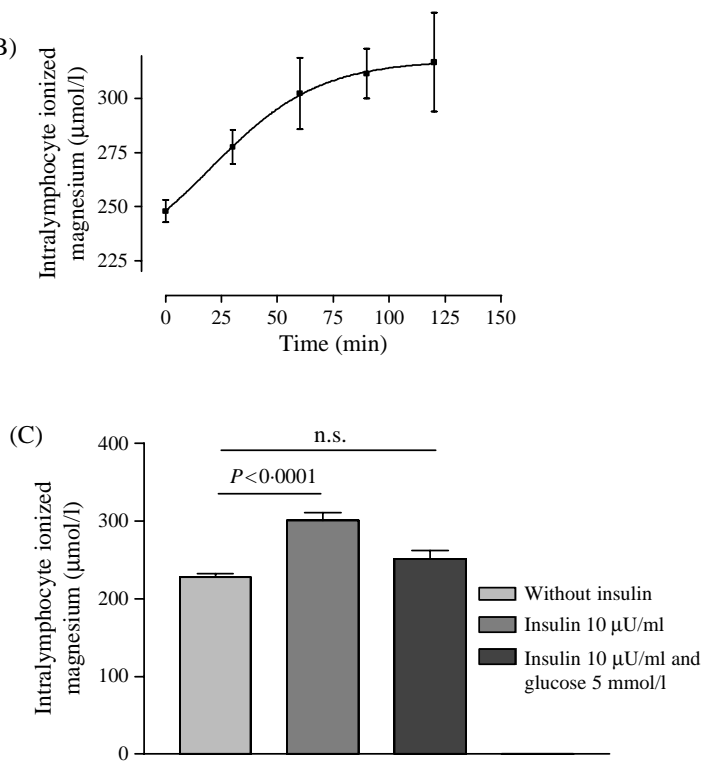

Figure 1 (A) Dose-response curves of $\mathrm{Mg}_{i}^{2+}$ to insulin at three extracellular glucose concentrations (5, 7 and $15 \mathrm{mmol} / \mathrm{l})$. The halfmaximal effect $\left(E_{50}\right)$ for the three curves is approximately equal $\left(0 \cdot 15 \mu \mathrm{U} / \mathrm{ml}\right.$ insulin) and three statistically different maximal $\mathrm{Mg}_{i}^{2+}$ values were found. One preparation of lymphocytes was exposed to one concentration of glucose and five different concentrations of insulin. The lymphocytes used for these experiments belong to a single donor. (B) Time course of the insulin-induced $(10 \mu \mathrm{U} / \mathrm{ml})$ $\mathrm{Mg}_{i}^{2+}$ increase in human lymphocytes. (C) Bar graph showing the in vitro effect of $10 \mu \mathrm{U} / \mathrm{ml}$ insulin on $\mathrm{Mg}_{i}^{2+}$ in human lymphocytes in the absence and presence of $5 \mathrm{mmol} / /$ glucose. Each point is the mean \pm s.D. obtained using six different preparations of lymphocytes.

Effects of differential permeabilization of lymphocytes on insulin-induced $\mathrm{Mg}_{i}^{2+}$ increases

In the absence of insulin, the lymphocyte whole-cell $\mathrm{Mg}_{i}^{2+}$, the digitonin-treated lymphocyte $\mathrm{Mg}_{i}^{2+}$ (compartmentalized $\left.\mathrm{Mg}_{i}^{2+}\right)$ and the lymphocyte cytosolic $\mathrm{Mg}_{i}^{2+}$ were $126 \pm 23$, $20 \pm 7,106 \pm 23 \mu \mathrm{M}$, respectively $(n=5)$. In the presence of $10 \mu \mathrm{U} / \mathrm{ml}$ insulin, these values were $177 \pm 26,29 \pm 4$, and 
Table 1 Effect of different in vitro treatments on the insulin-induced $\mathrm{Mg}_{\mathrm{i}}{ }^{2+}$ increase in human lymphocytes

\begin{tabular}{|c|c|c|c|}
\hline$n$ & $\begin{array}{l}\text { Intralymphocyte } \\
\mathbf{M g}_{i}^{2+} \text { concentration } \\
(\mu \mathrm{M})\end{array}$ & $P$ value & $\mathbf{C I}(\mu \mathrm{M})$ \\
\hline 12 & $227 \pm 14$ & & \\
\hline 12 & $301 \pm 25$ & $P<0 \cdot 001$ vs control cells without insulin & $52-94$ \\
\hline 6 & $165 \pm 15$ & $P<0 \cdot 01$ vs control cells without insulin & $17-59$ \\
\hline 4 & $305 \pm 38$ & $P<0.01$ vs control cells without insulin & $40-87$ \\
\hline 4 & $335 \pm 36$ & $P<0 \cdot 001$ vs control cells without insulin & 50-97 \\
\hline 3 & $78 \pm 18$ & & \\
\hline 6 & $135 \pm 20$ & $P<0 \cdot 003$ & $50-120$ \\
\hline 6 & $230 \pm 50$ & & \\
\hline 6 & $570 \pm 65$ & $P<0 \cdot 0001$ & $210-400$ \\
\hline 6 & $530 \pm 60$ & $P<0 \cdot 0001$ & $100-270$ \\
\hline
\end{tabular}

All measurements were performed after $2 \cdot 5 \mathrm{~h}$; insulin when indicated is $10 \mu \mathrm{U} / \mathrm{ml}$. Mean \pm s.D. values of 3-12 independent experiments were provided; Cl: $95 \%$ confidence limits. 2-DOG: 2-deoxy-D-glucose.

Table 2 Combined effect of insulin and inhibitors or regulators of transmembrane $\mathrm{Mg}^{2+}$ fluxes in human lymphocytes

\section{Intralymphocyte $\mathbf{M g}_{\mathbf{i}}{ }^{2+}$} concentration $(\mu \mathrm{M})$

$P$ value

\section{Treatment}

Control cells $\left(\mathrm{Na}^{+}\right.$medium) without insulin

Control cells $\left(\mathrm{Na}^{+}\right.$medium) with insulin

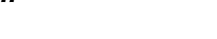

$227 \pm 14$

$301 \pm 25$

$789 \pm 51$

$749 \pm 12$

$300 \pm 12$

Choline $\mathrm{Na}^{+}$substitution medium with insulin

$230 \pm 27$

$500 \mu \mathrm{mol} / /$ imipramine with insulin

$240 \pm 26$

$297 \pm 10$

$206 \pm 23$

$238 \pm 18$

$231 \pm 25$

$243 \pm 19$

$276 \pm 20$

$3 \mathrm{mmol} / \mathrm{l}$ extracellular $\mathrm{Mg}^{2+}$ without insulin

$0 \mathrm{mmol} / \mathrm{l}$ extracellular $\mathrm{Mg}^{2+}$ with insulin

$0.8 \mathrm{mmol} / \mathrm{l}$ extracellular $\mathrm{Mg}^{2+}$ with insulin

$271 \pm 22$

$P<0 \cdot 001$ vs control cells without insulin

$P<0.001$ vs control cells without insulin

$P<0 \cdot 001$ vs control cells with insulin

$P<0 \cdot 001$ vs control cells without insulin

$452-592$
$330-469$

49-100

$P<0 \cdot 001$ vs control cells without insulin

48-95

$P<0.05$ vs $0 \mathrm{mmol} / \mathrm{l}$ extracellular $\mathrm{Mg}^{2+}$ without insulin

$P<0.05$ vs $0.8 \mathrm{mmol} / /$ extracellular $\mathrm{Mg}^{2+}$ without insulin

$25-50$

$P<0.05$ vs $3 \mathrm{mmol} / \mathrm{l}$ extracellular $\mathrm{Mg}^{2+}$ without insulin

20-60

23-49

All measurements were performed after $2 \cdot 5 \mathrm{~h}$; insulin when indicated is $10 \mu \mathrm{U} / \mathrm{ml}$; in experiments conducted with different extracellular magnesium concentrations a different medium was used (Bulher solution) as compared with the others ( $\mathrm{Na}^{+}$medium)— for details see Delva et al. (1998b). Mean \pm s.D. values of 3-12 independent experiments were provided; Cl: $95 \%$ confidence limits. 
$147 \pm 22 \mu \mathrm{M}$, ANOVA: $\mathrm{F}=7 \cdot 59, P=0 \cdot 002$, respectively $(n=5)$. In the presence and absence of $10 \mu \mathrm{U} / \mathrm{ml}$ of insulin, the $\mathrm{Mg}_{i}^{2+}$ concentrations relating to lymphocyte whole-cell $\mathrm{Mg}_{i}^{2+}$, compartmentalized $\mathrm{Mg}_{i}^{2+}$ and cytosolic $\mathrm{Mg}_{i}^{2+}$, were all statistically significantly different $(P=0 \cdot 01)$.

Under our experimental conditions, the incubation of lymphocytes for $2.5 \mathrm{~h}$ with $10 \mu \mathrm{U} / \mathrm{ml}$ of insulin did not produce any statistically significant modifications in the concentration of $\mathrm{ATP}_{\mathrm{i}}$, (control medium, $5 \cdot 31 \pm 0 \cdot 73 \mathrm{mM}$; insulin-treated, $5 \cdot 78 \pm 0 \cdot 85 \mathrm{mM}, n=6)$.

Total intracellular magnesium in lymphocytes incubated in the medium without insulin was $19 \pm 2 \mathrm{mM} \quad(n=12)$. Incubation of lymphocytes for $2 \cdot 5 \mathrm{~h}$ with $10 \mu \mathrm{U} / \mathrm{ml}$ of insulin did not significantly modify this value (glucosetreated, $18 \cdot 7 \pm 1 \cdot 5 \mathrm{mM}, n=12$ ).

As far as ionized intracellular calcium is concerned, incubation of lymphocytes for $2.5 \mathrm{~h}$ with $100 \mu \mathrm{U} / \mathrm{ml}$ of insulin did not modify the concentration of $\mathrm{Ca}_{i}^{2+}$ in lymphocytes (without insulin, $60 \pm 11 \mathrm{nM}$, with insulin $65 \pm 12, n=8)$.

\section{Discussion}

Incubation of human lymphocytes with insulin at concentrations that mimic both physiological and pathological situations results in a significant increase in the $\mathrm{Mg}_{i}^{2+}$ concentration, confirming data obtained from anucleated human-derived cells such as erythrocytes (Barbagallo et al. 1993, 1997) and platelets (Hwang et al. 1993). However, in these previous studies, the interrelationships between intracellular magnesium, glucose and insulin were not investigated.

Paolisso et al. (1986) were the first to show in human erythrocytes that insulin in vitro increases erythrocyte magnesium, an effect that is entirely abolished by ouabain. The same authors then showed that the insulin-induced magnesium increase in erythrocytes is different in patients with type 2 diabetes (Paolisso et al. 1988) or obese subjects (Paolisso et al. 1990) compared with healthy subjects.

Dominguez et al. (1998) confirmed in human erythrocytes that insulin is capable of increasing intracellular free magnesium in a dose- and time-dependent manner (Barbagallo et al. 1993) and that IGF-1 has a similar effect.

Hwang et al. (1993) confirmed these results in a different cell model, namely the human platelet, and showed that insulin had a dose- and time-dependent effect on the increase of $\left[\mathrm{Mg}^{2+}\right]_{\mathrm{i}}$ and suggested that insulin can translocate $\mathrm{Mg}^{2+}$ from the extracellular space. Takaya et al. (1998) confirmed and extended the results on human platelets showing that IGF-1 produces the same increases in $\mathrm{Mg}_{i}^{2+}$ as insulin. The involvement of $\mathrm{Na}^{+}-\mathrm{Mg}^{2+}$ exchanger was judged as improbable and insulin/IGF-1 translocates $\mathrm{Mg}^{2+}$ from the extracellular space.

To our knowledge, only Hua et al. (1995) have studied the in vitro effects of insulin on human resting lymphocytes and confirmed the results obtained from erythrocytes and platelets by demonstrating that insulin in vitro can increase $\mathrm{Mg}_{i}^{2+}$ in human resting lymphocytes. The results obtained from the present work are in agreement with the above results obtained from a different cell model utilizing different methodological approaches. As far as we know, the only study performed in insulin-target cells was performed in rat hepatocytes by Keenan et al. (1996), who demonstrated that insulin is able to block the $\mathrm{Mg}^{2+}$ efflux from perfused rat livers stimulated by isoproterenol.

We have previously studied the in vitro effect of glucose alone on $\mathrm{Mg}_{i}^{2+}$ in human lymphocytes and found that in the absence of insulin, glucose is capable of decreasing the $\mathrm{Mg}_{i}^{2+}$ in a dose-dependent and stereospecific manner (Delva et al. 2002). The glucose-induced increase in intracellular ATP, binding a greater amount of $\mathrm{Mg}_{i}^{2+}$ and forming $\mathrm{MgATP}$, seems to be the most likely cause for the glucose-induced decrease in ionized magnesium (Delva et al. 2002).

In the present paper, we studied the in vitro effects of insulin, both alone or in combination with glucose, on lymphocyte $\mathrm{Mg}_{i}^{2+}$. The latter situation, i.e. the interaction between insulin, glucose, and $\mathrm{Mg}_{i}^{2+}$, which obviously tries to mimic the physiological situation, is complex. As shown in Fig. 1A, insulin is capable of significantly increasing the $\mathrm{Mg}_{i}^{2+}$ in all glucose concentrations tested, which were intended to mimic conditions of overt hyperglycemia $(15 \mathrm{mmol} / \mathrm{l})$, hyperglycemia $(10 \mathrm{mmol} / \mathrm{l})$ and fasting $(5 \mathrm{mmol} / \mathrm{l})$. From a kinetic point of view, the three dose-response curves are sigmoidal with approximately the same $\mathrm{EC}_{50}$. The time courses of the insulin-induced increase in $\mathrm{Mg}_{i}^{2+}$ (Fig. 1B) and glucose-induced decreases in $\mathrm{Mg}_{i}^{2+}$ (Delva et al. 2002) are superimposable as far as the timing of initial and maximal effect are concerned. The effect of both insulin and glucose on intralymphocyte-ionized magnesium does not begin immediately, but takes place after about $30 \mathrm{~min}$.

Regarding the mechanisms involved in the insulinmediated increase of $\mathrm{Mg}_{i}^{2+}$, the lack of effects of inhibitors of the membrane $\mathrm{Na}^{+}-\mathrm{K}^{+}$pump (ouabain) and membrane $\mathrm{Na}^{+}-\mathrm{K}^{+}{ }_{-} \mathrm{Cl}^{-}$cotransport (bumetanide) on the insulinmediated increase of $\mathrm{Mg}_{i}^{2+}$ is at odds with the possibility that these membrane transport systems are involved. The substitution of extracellular sodium with choline, which blocks the membrane $\mathrm{Na}^{+}-\mathrm{Mg}^{2+}$ exchanger, abolishes the insulin-mediated increase of $\mathrm{Mg}_{i}^{2+}$. However, since the method for blocking the $\mathrm{Na}^{+}-\mathrm{Mg}^{2+}$ exchanger increases cytosolic $\mathrm{Mg}^{2+}$ to a very high level and may even be toxic, we used two well-known inhibitors of the $\mathrm{Na}^{+}-\mathrm{Mg}^{2+}$ exchanger: imipramine and quinidine (Feray and Garay 1986). In the presence of either inhibitor, no increase in $\mathrm{Mg}_{i}^{2+}$ was induced by insulin. This is in favor of the hypothesis that insulin is capable of increasing the $\mathrm{Mg}_{i}^{2+}$ by inhibiting this membrane transport.

In contrast with previous data (Romani et al. 2000), insulin is capable of increasing the $\mathrm{Mg}_{i}^{2+}$ even in the absence of extracellular glucose or magnesium. This latter fact would exclude that an $\mathrm{Ca}_{\mathrm{o}}^{2+}-\mathrm{Mg}_{i}^{2+}$ exchanger or an inwardly directed $\mathrm{Mg}^{2+}$ channel is involved in the process. By 
increasing the extracellular magnesium from 0 to $3 \mathrm{mmol} / \mathrm{l}$, the $\mathrm{Mg}_{i}^{2+}$ increases progressively both in the absence and presence of insulin. In fact, the two curves are parallel, which, together with the lack of modification of total intracellular magnesium in the presence of insulin, suggests that the insulin-induced increase in $\mathrm{Mg}_{i}^{2+}$ is not due to increases in passive permeability. Data obtained with differential membrane permeabilization do not seem to localize the insulinmediated increase of $\mathrm{Mg}_{i}^{2+}$ either in the cytosol or in cellular organelles.

In order to better understand the mechanism of the insulin effects on $\mathrm{Mg}_{i}^{2+}$, we evaluated molecules characterized by an insulin-mimicking action such as IGF-1 and vanadate. Dominguez et al. (1998) were the first to test in vitro the effects of IGF-1 on intracellular magnesium. IGF-1 is capable of increasing $\mathrm{Mg}_{i}^{2+}$ in erythrocytes from normotensive and hypertensive subjects. The results in which no effects of IGF-1 could be detected on lymphocyte $\mathrm{Mg}_{i}^{2+}$ are difficult to compare to those obtained by Dominguez et al. (1998) because different cell models and analytical methods were used. Barbagallo et al. (2001) have been the only investigators to assess the effect of vanadate on intracellular magnesium compared to the effects of insulin. In the experimental conditions utilized (in the erythrocyte measuring with nuclear magnetic resonance), vandate increased $\mathrm{Mg}_{i}^{2+}$ in a manner that was comparable to insulin at a concentration of $50 \mu \mathrm{mol} / \mathrm{l}$, while at a concentration of $1 \mathrm{mmol} / \mathrm{l}$, it had the opposite effect and produced a decrease. We tested two concentrations of vanadate on lymphocytes. At high concentrations $(1 \mathrm{mmol} / \mathrm{l})$, it decreased $\mathrm{Mg}_{i}^{2+}$, while at $50 \mu \mathrm{mol} / \mathrm{l}$, vanadate did not show any effect on lymphocyte magnesium. The discrepancy of the effects of vanadate on $\mathrm{Mg}_{i}^{2+}$ in lymphocytes with respect to erythrocytes is difficult to reconcile with the current cellular model and the different methods of measurement. However, if this were the case, our results would also be different for insulin, which is in agreement with published studies. Our data suggests that in lymphocytes, vanadate does not mimic insulin action. The decrease in $\mathrm{Mg}_{i}^{2+}$ seen at high concentrations may be attributable to the toxicity of vanadate on various membrane transport systems (Domingo 2002).

PI 3-kinase is known to be a part of the signaling pathways for $\mathrm{Na}^{+}$transporters. In adipose tissue, PI 3-kinase has been shown to be activated by insulin and to mediate the effect of insulin on glucose transport. To examine the role of PI 3-kinase on insulin-induced $\mathrm{Mg}_{i}^{2+}$ increase, we measured ionized magnesium in lymphocytes incubated with insulin in the presence and absence of wortmannin (WT), an established inhibitor of PI 3-kinase. Incubation of lymphocytes with $100 \mu \mathrm{U} / \mathrm{ml}$ insulin and $0 \cdot 1 \mu \mathrm{mol} / 1 \mathrm{WT}$ completely blocked the insulin-stimulated $\mathrm{Mg}_{i}^{2+}$ increase, suggesting yet another role for the PI 3-kinase pathway in insulin-mediated cellular events. Ferreira et al. (2003) showed that insulin-stimulated $\mathrm{Mg}^{2+}$ efflux from $\mathrm{Mg}^{2+}$-loaded erythrocytes is blocked by WT. Despite this, an insulin-stimulated $\mathrm{Mg}_{i}^{2+}$ magnesium efflux does not explain the insulin-stimulated $\mathrm{Mg}_{i}^{2+}$ increase that we observed.

The use of 1,2-dioctanoyl-sn-glycerol, a cell-permeable diacylglycerol analog, mimics the effect of insulin on $\mathrm{Mg}_{i}^{2+}$, suggesting that insulin may act on intracellular $\mathrm{Mg}_{i}^{2+}$ at least in part by activation of protein kinase C (PKC).

Finally, we utilized iodoacetic acid to inhibit the hexose monophosphate shunt, and 2-deoxy-D-glucose to inhibit glycolysis. Both substances greatly increased $\mathrm{Mg}_{i}^{2+}$, as shown in Table 1, and we propose that it is likely to be due to a decrease in intracellular ATP and the consequent increase in free, unbound magnesium. The massive increase of ionized intracellular magnesium produced by both these substances prevents the measurement of any additional effects of insulin.

Even though the calcium determination was not the main aim of the study, intralymphocyte-free calcium was also measured, mainly to exclude substantial intracellular calcium increase that may theoretically affect magnesium determinations (Hurley et al. 1992). Insulin did not alter the $\mathrm{Ca}_{i}^{2+}$, thus confirming the results obtained in vitro in other cell models (Thomas et al. 1985).

In conclusion, we have shown for the first time in human nucleated cells the ability of insulin to modify in vitro the concentration of $\mathrm{Mg}_{i}^{2+}$ through a mechanism based on activation of a $\mathrm{Na}^{+}-\mathrm{Mg}^{2+}$ membrane transport system, possibly through the mediation of PI 3-kinase and PKC activation. Taking into account the relationship between insulin and glucose plasma levels and their opposite effects on $\mathrm{Mg}_{i}^{2+}$, this may represent the two limbs of a biphasic regulatory system of $\mathrm{Mg}_{i}^{2+}$ in both physiological and pathological conditions. An increase of insulin in response to eating, and therefore before an increase in plasma glucose levels, can be hypothesized, increasing $\mathrm{Mg}_{i}^{2+}$ and augmenting the activity of enzymes involved in glucose metabolism to bring about conditions that are more appropriate for metabolism and production of energy. Moreover, this effect would be produced as a final result of the increased enzymatic velocity and decrease in the extracellular concentration of glucose to reestablish glucose homeostasis. The decrease in extracellular glucose thus obtained would bring about a decrease in insulinemia that would precede a decrease in $\mathrm{Mg}_{i}^{2+}$, with reestablishment of cellular magnesium. In type 1 or 2 diabetes mellitus, the elevated plasma glucose concentrations in the absence of insulin or in situations of peripheral resistance to its actions would produce a prevailing effect, decreasing the inhibition of $\mathrm{Mg}_{i}^{2+}$. This would lead to a slowing of glucose degradation and would negatively influence magnesium-dependent enzymatic reactions. In addition, it would explain the frequent observation of reduced intracellular magnesium concentrations in patients with diabetes mellitus (Paolisso et al. 1988).

It is clear that this mechanism, which has been shown in lymphocytes, cannot easily be extrapolated to other 
cellular models that are much more important in the physiopathology of glucose metabolism, both in physiological conditions and in diabetes mellitus. Despite this, a direct correlation has been described between the concentration of magnesium in lymphocytes and that in striated muscular tissue (Dyckner and Wester 1985). It must also be remembered that some authors have shown that there is an alteration of pyruvate dehydrogenase (Curto et al. 1997) in the lymphocytes of patients with type 2 diabetes mellitus, which is in agreement with studies carried out in adipocytes (Mandarino et al. 1986) and in skeletal muscle (Kelley et al. 1992) of patients with type 2 diabetes mellitus. Finally, several investigators have described the presence of GLUT3 in human lymphocytes (Estrada et al. 1994), which is a transporter in some cell types that have been shown to be insulin sensitive (Bilan et al. 1992). Estrada et al. (1994) have also demonstrated that in contrast to monocytes, lymphocytes show a significant increase in the expression of GLUT3 in patients with insulin-dependent diabetes mellitus with respect to healthy control subjects.

\section{Funding}

The present study was supported by grants from University of Verona (Fondi di Ateneo), Italy. The authors declare that there is no conflict of interest that would prejudice the impartiality of this scientific work.

\section{References}

Barbagallo M, Gupta RK \& Resnick LM 1993 Cellular ionic effects of insulin in normal human erhythrocytes: a nuclear magnetic resonance study. Diabetologia 36 146-149.

Barbagallo M, Gupta RK, Bardicef O, Bardicef M \& Resnick LM 1997 Altered ionic effects of insulin in hypertension: role of basal ion levels in determining cellular responsiveness. Journal of Clinical Endocrinology and Metabolism 82 1761-1765.

Barbagallo M, Dominguez LJ \& Resnick LM 2001 Insulin-mimetic action of vanadate. Role of intracellular magnesium. Hypertension 38 701-704.

Bilan P, Mitsumoto Y, Maher F, Simpson IA \& Klip A 1992 Detection of the GLUT3 facilitative glucose transporter in rat L6 muscle cells: regulation by cellular differentiation, insulin and IGF-I. Biochemical and Biophysical Research Communications 186 1129-1137.

Curto M, Novi RF, Rabbone I, Maurino M, Piccinini M, Mioletti S, Mostert M, Bruno R \& Rinaudo MT 1997 Insulin resistance in obese subjects and newly diagnosed NIDDM patients and derangements of pyruvate dehydrogenase in their circulating lymphocytes. International Journal of Obesity 21 1137-1142.

Delva P, Pastori C, Degan M, Montesi G \& Lechi A 1996 Intralymphocyte free magnesium in a group of subjects with essential hypertension. Hypertension 28 433-439.

Delva P, Pastori C, Degan M, Montesi G \& Lechi A 1998a Intralymphocyte free magnesium and plasma triglycerides. Life Sciences 62 2231-2240.

Delva P, Pastori C, Montesi G, Degan M, Micciolo R, Paluani F \& Lechi A 19986 Intralymphocyte free magnesium and calcium and insulin tolerance test in a group of essential hypertensive patients. Life Sciences 63 1405-1415.

Delva P, Degan M, Pastori C, Faccini G \& Lechi A 2002 Glucose-induced alterations of intracellular ionized magnesium in human lymphocytes. Life Sciences $712119-2135$.
Delva P, Pastori C, Degan M, Montesi G \& Lechi A 2004 Catecholamineinduced regulation in vitro and ex vivo of intralymphocyte ionized magnesium. Journal of Membrane Biology 199 163-171.

Domingo JL 2002 Vanadium and tungsten derivatives as antidiabetic agents: a review of their toxic effects. Biological Trace Element Research 88 97-112.

Dominguez LJ, Barbagallo M, Sowers JR \& Resnick LM 1998 Magnesium responsiveness to insulin and insulin-like growth factor I in erythrocytes from normotensive and hypertensive subjects. Journal of Clinical Endocrinology and Metabolism 83 4402-4407.

Dyckner T \& Wester PO 1985 Skeletal muscle magnesium and potassium determinations: correlations with lymphocyte contents of magnesium and potassium. Journal of the American College of Nutrition 4 619-625.

Elin JR \& Hosseine JM 1985 Magnesium content of mononuclear blood cells. Clinical Chemistry 31 377-380.

Estrada ED, Elliott E, Zinman B, Poon I, Liu Z, Klip A \& Daneman D 1994 Regulation of glucose transport and expression of GLUT3 transporters in human circulating mononuclear cells: studies in cells from insulin-dependent diabetic and nondiabetic individuals. Metabolism 43 591-598.

Feray JC \& Garay R $1986 \mathrm{An} \mathrm{Na}^{+}$-stimulated $\mathrm{Mg}^{2+}$-transport system in human red blood cells. Biochimica et Biophysica Acta 856 76-84.

Ferreira A, Rivera A \& Romero JR $2003 \mathrm{Na}^{+} / \mathrm{Mg}^{2+}$ exchange is functionally coupled to the insulin receptor. Journal of Cellular Physiology 199 434-440.

Grynkiewicz G, Poenie M \& Tsien RY 1985 A new generation of $\mathrm{Ca}^{2+}$ indicators with greatly improved fluorescence properties. Journal of Biological Chemistry $2603440-3450$.

Hua H, Gonzales J \& Rude RK 1995 Magnesium transport induced ex vivo by a pharmacological dose of insulin is impaired in non-insulin-dependent diabetes mellitus. Magnesium Research 8 359-366.

Hurley TW, Ryan MP \& Brinck RW 1992 Changes of cytosolic $\mathrm{Ca}^{2+}$ interfere with measurements of cytosolic $\mathrm{Mg}^{2+}$ using mag-fura-2. American Journal of Physiology 263 C300-C307.

Hwang DL, Yen CF \& Nadler JL 1993 Insulin increases intracellular magnesium transport in human platelets. Journal of Clinical Endocrinology and Metabolism 76 549-553.

Keenan D, Romani A \& Scarpa A 1996 Regulation of $\mathrm{Mg}^{2+}$ homeostasis by insulin in perfused rat livers and isolated hepatocytes. FEBS Letters 395 241-244.

Kelley DE, Mokan M \& Mandarino LJ 1992 Intracellular defects in glucose metabolism in obese patients with NIDDM. Diabetes 41 698-706.

Ma J, Folsom AR, Melnick SL, Eckfeldt JH, Sharrett AR, Nabulsi AA, Hutchinson RG \& Metcalf PA 1995 Associations of serum and dietary magnesium with cardiovascular disease, hypertension, diabetes, insulin and carotid arterial wall thickness: the ARIC study. Journal of Clinical Epidemiology 48 927-940.

Mandarino LJ, Madar Z, Kolterman OI, Bell JM \& Olefsky JM 1986 Adipocyte glycogen synthase and pyruvate dehydrogenase in obese and type II diabetic subjects. American Journal of Physiology 251 E489-E496.

Nieminen AL, Gores GJ, Dawson TL, Herman B \& Lemasters JJ 1990 Toxic injury from mercuric chloride in rat hepatocytes. Journal of Biological Chemistry 265 2399-2408.

Paolisso G, Sgambato S, Passariello N, Giugliano D, Scheen A, D’Onofrio F \& Lefebvre PJ 1986 Impaired insulin-mediated erythrocyte magnesium accumulation is correlated to impaired insulin-mediated glucose disposal in aged non-diabetic obese patients. Diabetologia 29 644-647.

Paolisso G, Sgambato S, Giugliano D, Torella R, Varricchio M, Scheen AJ, D'Onofrio F \& Lefebvre PJ 1988 Impaired insulin-induced erythrocyte magnesium accumulation is correlated to impaired insulin-mediated glucose disposal in type 2 (non-insulin-dependent) diabetic patients. Diabetologia 31 910-915.

Paolisso G, Pizza G, De Riu S, Marrazzo G, Sgambato S, Varricchio M \& D'Onofrio F 1990 Insulin induces opposite changes in plasma and erythrocyte magnesium concentrations in normal man Diabetes and Metabolism 16 328-333.

Raju B, Murphy E, Levy LA, Hall RD \& London RE 1989 A fluorescent indicator for measuring cytosolic free magnesium. American Journal of Physiology 256 C540-C548. 
Romani AMP, Matthews VD \& Scarpa A 2000 Parallel stimulation of glucose and $\mathrm{Mg} 2+$ accumulation by insulin in rat hearts and cardiac ventricular myocytes. Circulation Research 86 326-333.

Schnack C, Bauer I, Pregant P, Hopmeier P \& Schernthaner G 1992 Hypomagnesemia in type 2 (non-insulin dependent) diabetes mellitus is not corrected by improvement of long-term metabolic control. Diabetologia 35 77-79.

Takaya J, Higashino H, Miyazaki R \& Kobayashi Y 1998 Effects of insulin and insulin-like growth factor-1 on intracellular magnesium of platelets. Experimental and Molecular Pathology 65 104-109.
Thomas AP, Martin-Requero A \& Williamson JR 1985 Interactions between insulin and $\alpha 1$-adrenergic agents in the regulation of glycogen metabolism in isolated hepatocytes. Journal of Biological Chemistry 260 5963-5973.

Received in final form 15 April 2006

Accepted 28 April 2006

Made available online as an Accepted Preprint 11 May 2006 